\title{
Optimizing pre-, intra-, and postoperative management of patients with sellar pathology undergoing transsphenoidal surgery
}

\author{
David J. Cote, PhD, ${ }^{1}$ Sherry L. Iuliano, NP, ${ }^{1}$ Michael P. Catalino, MD, MSc, ${ }^{1,2}$ and \\ Edward R. Laws Jr., MD1 \\ 1Pituitary/Neuroendocrine Center, Brigham and Women's Hospital, Harvard Medical School, Boston, Massachusetts; and \\ 2Department of Neurosurgery, University of North Carolina, Chapel Hill, North Carolina
}

\begin{abstract}
OBJECTIVE Perioperative management of patients with sellar lesions is complex, requiring input from a multidisciplinary team of specialists for ongoing management of both endocrinological and neurosurgical issues. Here, the authors reviewed the experience of a single multidisciplinary center over 10 years to identify key postoperative practices that ensure positive outcomes for patients with sellar lesions who undergo transsphenoidal surgery.

METHODS The authors performed a retrospective review of all transsphenoidal operations carried out by the senior author at a single center from April 2008 through November 2018. They included only adult patients and recorded perioperative management. They also reviewed the evolution of clinical practices for perioperative care at their institution to identify strategies for ensuring positive patient outcomes, and they reviewed the literature on select related topics.

RESULTS In total, 1023 operations in 928 patients were reviewed. Of these, 712 operations were for pituitary adenomas (69.6\%), and 122 were for Rathke cleft cysts (11.9\%). The remainder included operations for craniopharyngiomas (3.6\%), arachnoid cysts $(1.7 \%)$, pituitary tumor apoplexy $(1.0 \%)$, and other sellar pathologies $(12.2 \%)$. Among the reviewed operations, the median hospital stay was 3 days (IQR 2-3). Patient management details during the pre-, intra-, and postoperative periods were identified, including both shared characteristics of all patients undergoing transsphenoidal surgery and unique characteristics that are specific to certain lesion types or patient populations.
\end{abstract}

CONCLUSIONS Patients with sellar lesions who undergo transsphenoidal surgery require complex, multidisciplinary perioperative care to monitor for common adverse events and to improve outcomes, but there is a dearth of high-quality evidence guiding most perioperative practices. Here, the authors reviewed practices at their institution across more than 1000 transsphenoidal operations that may help ensure successful patient outcomes.

https://thejns.org/doi/abs/10.3171/2020.3.FOCUS2043

KEYWORDS pituitary adenoma; postoperative; hormone replacement; hyponatremia

$\mathrm{T}$ HE sellar region is one of the most common sites of intracranial disease. ${ }^{13,40} \mathrm{~A}$ wide range of lesions can affect the sella, including pituitary adenomas, Rathke cleft cysts, craniopharyngiomas, and, less commonly, metastases and lymphomas, among others..$^{12}$ Pituitary adenomas, the most common sellar lesion, have an estimated prevalence as high as $20 \%$, based on autopsy and radiological studies, and are often identified incidentally. 13,14,40

Although often asymptomatic, lesions of the sellar region can have devastating effects due to mass effect on surrounding structures, including the pituitary gland and the optic chiasm. ${ }^{24,49}$ Common presenting symptoms in patients with sellar disease include headache, visual disturbances, and hypopituitarism, which can progress to permanent disease or can resolve with appropriate treatment. Patients with sellar lesions requiring surgical intervention most commonly undergo transsphenoidal treatment, in which surgeons use either the operating microscope or endoscope. . $^{218,42}$

Besides optimizing general preoperative cardiovascular conditioning, there are shared and unique modifiable variables of each subset of patients that can be leveraged to optimize surgical outcomes. The perioperative manage-

ABBREVIATIONS DI = diabetes insipidus; IPSS = inferior petrosal sinus sampling; NSAID = nonsteroidal antiinflammatory drug

SUBMITTED January 24, 2020. ACCEPTED March 3, 2020

INCLUDE WHEN CITING DOI: 10.3171/2020.3.FOCUS2043. 
ment of patients with sellar lesions is complicated by the delicate nature of the affected structures and the complexity of the underlying disease. Shared variables include operating room ergonomics for the patient and surgeon, preservation of normal pituitary gland, proper reconstruction of the skull base, operative time, postoperative mobility, pain control, monitoring for new hypopituitarism, and prevention of hyponatremia. Unique modifiable variables are typically dictated by the preoperative diagnosis. The diagnoses that most require specific perioperative consideration are acromegaly, Cushing's disease, and macro- or giant adenomas with compression of the optic apparatus, along with those patients requiring complex skull base reconstruction. $4,16,22,26,32,41,46,51$

The most common adverse events after transsphenoidal surgery for sellar pathology include hyponatremia, hypopituitarism, CSF leak, and epistaxis. Patients require careful monitoring for these problems, and institutional protocols in the perioperative period can help limit their occurrence. ${ }^{6,7}$ Many of these patients also require longterm follow-up for management of endocrinological and neurosurgical issues, but few studies have discussed the optimum strategy for postoperative management in this patient population. ${ }^{15}$

We aimed to describe the experience of our institution in the pre-, intra-, and postoperative management of a broad range of patients with sellar pathology who undergo transsphenoidal surgery. Evolving during more than 1000 operations at our center, an effective and user-friendly routine has been developed. This routine has resulted in improved outcomes, fewer readmissions, and fewer complications. Patient compliance and satisfaction also continue to improve. An integral part is nursing and patient education and teamwork. The details of our practice are outlined, with commentary, and a review of the literature on select topics was performed.

\section{Methods}

We performed a retrospective review of all transsphenoidal operations carried out by the senior author at a single center from April 2008 through November 2018. We included only adult patients and recorded preoperative demographics and lesion characteristics. We also reviewed clinical practices at our center for the care of patients undergoing transsphenoidal surgery. These were divided into the pre-, intra-, and postoperative periods, including longterm follow-up. We also grouped important preoperative characteristics into shared and unique variables in order to underscore the importance of individualized patient management within a general, structured, perioperative institutional protocol. A literature review was performed for each topic to accompany the institutional perspective and results.

\section{Results}

\section{Patient Demographics and Characteristics}

From April 2008 through November 2018, 928 patients underwent 1023 operations for sellar pathology performed by the senior author (Table 1). Of these operations, 440
TABLE 1. Characteristics of transsphenoidal operations, 2008-2018

\begin{tabular}{|c|c|}
\hline Characteristic & Total Operations $(n=1023)$ \\
\hline \multicolumn{2}{|l|}{ Demographics } \\
\hline Male sex, $\mathrm{n}(\%)$ & $440(43.0)$ \\
\hline Age in yrs, median (IQR) & $48(35,60)$ \\
\hline BMI, median (IQR) & $28.3(24.9,32.4)$ \\
\hline \multicolumn{2}{|l|}{ Lesion type, n (\%) } \\
\hline Adenoma & $712(70.0)$ \\
\hline Nonfunctioning adenoma & $309(43.4)$ \\
\hline $\mathrm{GH}$ & $125(17.6)$ \\
\hline ACTH & $120(16.9)$ \\
\hline PRL & $86(12.1)$ \\
\hline $\mathrm{FSH} / \mathrm{LH}$ & $50(7.0)$ \\
\hline Adenoma, unspecified & $16(2.2)$ \\
\hline TSH & $6(0.8)$ \\
\hline Rathke cleft cyst & $122(11.9)$ \\
\hline Craniopharyngioma & $37(3.6)$ \\
\hline Arachnoid cyst & $17(1.6)$ \\
\hline Apoplexy & $10(1.0)$ \\
\hline Other & $125(12.2)$ \\
\hline \multicolumn{2}{|l|}{ Tumor characteristics* } \\
\hline Max diameter in $\mathrm{cm}$, median (IQR) & $1.80(1.1,2.5)$ \\
\hline Tumor vol in $\mathrm{cm}^{2}$, median (IQR)† & $2.28(0.7,5.5)$ \\
\hline \multicolumn{2}{|l|}{ Hospital characteristics } \\
\hline Length of stay in days, median (IQR) & $3.0(2.0,3.0)$ \\
\hline ICU admission, $\mathrm{n}(\%)$ & $128(12.5)$ \\
\hline
\end{tabular}

$\mathrm{ACTH}=$ adrenocorticotropic hormone; $\mathrm{FSH}=$ follicle-stimulating hormone; $\mathrm{GH}$ = growth hormone; $\mathrm{LH}=$ luteinizing hormone; $\mathrm{PRL}=$ prolactin; $\mathrm{TSH}=$ thyroidstimulating hormone.

* Where applicable.

$\dagger$ Computed using $\mathrm{ABC} / 2$ method.

(43.0\%) were in male patients, and the median age was 48 years (IQR 24.9-32.4). The most common lesion type was pituitary adenoma in 712 operations $(70.0 \%)$, followed by Rathke cleft cyst in 122 operations (11.9\%), craniopharyngioma in 37 operations (3.6\%), arachnoid cyst in 17 operations (1.6\%), and pituitary tumor apoplexy in 10 operations (1.0\%). Other sellar pathologies were present in 125 operations $(12.2 \%)$.

\section{Preoperative Management}

All patients undergoing transsphenoidal surgery at our multidisciplinary center undergo careful preoperative evaluation with both a neurosurgeon and a neuroendocrinologist. Physical examination focuses on the main presenting symptoms of sellar lesions, including visual fields and symptoms of hypo- and hyperpituitarism. Laboratory evaluation in all patients includes evaluation of all pituitary axes (Table 2), as well as serum sodium, in addition to standard preoperative laboratory examinations. Patients with evidence of low free thyroxine and morning cortisol are started on replacement therapy preoperatively. The biochemical diagnosis of acromegaly and Cushing's 
TABLE 2. Preoperative pituitary laboratory evaluation of patients with sellar pathology

\begin{tabular}{|c|c|}
\hline Laboratory Test & Rationale \\
\hline $\mathrm{ACTH}$ & $\begin{array}{l}\text { Measure of central response to peripheral cortisol levels. Helpful but not sufficient for the diagnosis of secondary adrenal insuf- } \\
\text { ficiency, Cushing's disease, or exogenous/ectopic Cushing's syndrome. }\end{array}$ \\
\hline Cortisol & Morning fasting cortisol level is helpful in the diagnosis of adrenal insufficiency. \\
\hline PRL & $\begin{array}{l}\text { Helpful in the diagnosis of prolactinomas \& stalk effect from compression of normal descending inhibitory dopamine effect on } \\
\text { lactotrophs. }\end{array}$ \\
\hline $\mathrm{GH}$ & $\begin{array}{l}\text { Measure of central production of GH. Useful for diagnosis of acromegaly when performing oral glucose tolerance test. Level fluctu- } \\
\text { ates significantly \& thus spot-checking is not specific for disease. }\end{array}$ \\
\hline IGF-1 & Peripheral measure of longstanding excess or deficiency of GH. \\
\hline $\mathrm{FSH}$ & $\begin{array}{l}\text { Useful for diagnosis of menopause, but in premenopausal women, menstrual cycle is the best predictor of intact hypothalamic- } \\
\text { pituitary-gonadal axis. }\end{array}$ \\
\hline $\mathrm{LH}$ & $\begin{array}{l}\text { Useful for diagnosis of menopause but in premenopausal women, menstrual cycle is the best predictor of intact hypothalamic- } \\
\text { pituitary-gonadal axis. }\end{array}$ \\
\hline Testosterone & Peripheral measure of hypothalamic-pituitary-gonadal axis in men. \\
\hline Estradiol & Peripheral measure of hypothalamic-pituitary-gonadal axis in women. \\
\hline $\mathrm{TSH}$ & $\begin{array}{l}\text { Measure of central response to peripheral thyroxine \& triiodothyronine levels. Helpful for diagnosis of central hypothyroidism if TSH } \\
\text { \& T4 are low or in diagnosis of thyrotroph hyperplasia or primary hypothyroidism, which can mimic adenomas radiologically (TSH } \\
\text { is typically elevated) but should be treated with levothyroxine first. }\end{array}$ \\
\hline Free thyroxine & $\begin{array}{l}\text { Measure of peripheral thyroxine \& a key modifiable endocrinopathy if low prior to surgery. Adrenal insufficiency should always be } \\
\text { addressed first to prevent adrenal crisis from selective thyroid replacement \& increased metabolic demand. }\end{array}$ \\
\hline
\end{tabular}

IGF-1 = insulin-like growth factor-1.

disease is beyond the scope of this paper, but guidelines are readily available, and careful diagnosis preoperatively in the setting of suspected disease is imperative. ${ }^{20,34} \mathrm{~Pa}-$ tients with elevated prolactin levels should be considered for medical therapy in the form of a dopamine agonist, although, in certain patients, mild hyperprolactinemia may occur secondary to compression of the pituitary stalk. ${ }^{43}$ Prolactinoma volume impacts prolactin level, and prolactin cutoffs vary by adenoma size when determining the likelihood of stalk compression as the cause of hyperprolactinemia. ${ }^{8}$ All patients undergo preoperative MRI with dedicated sequences for intraoperative image guidance. Patients are instructed to discontinue anticoagulants, including aspirin, antiplatelet agents, nonsteroidal antiinflammatory drugs (NSAIDs), and fish oils, after discussion with their primary physician. The preoperative discussion also includes expectations for the perioperative period, the inpatient stay, and postoperative pain. Additional consults are ordered as needed, and may include cardiology for patients who require cessation of anticoagulation, hematology for management of bleeding disorders, or otolaryngology for patients with complex nasal anatomy. All patients are also evaluated preoperatively by an experienced neuroanesthesiologist.

\section{Intraoperative Management}

The intraoperative management of patients undergoing transsphenoidal surgery at our institution follows a standard protocol, according to a previously published surgical checklist. ${ }^{23}$ Principles of management include strategies to improve patient satisfaction, shorten the hospital stay, and reduce the incidence of postoperative complications. Specifically, patients undergoing transsphenoidal surgery at our center rarely require a Foley catheter or arterial line placement due to short operative times for routine cases (typically 3 hours), and thus intravenous fluids are used as sparingly as possible to avoid postoperative hyponatremia. Patients with acromegaly are at risk for airway complications due to glottal and laryngeal anatomical enlargement, so preoperative discussion with the anesthesia team is imperative. ${ }^{41}$ Patients are carefully and ergonomically positioned in order to optimize venous return from the head and neck (thorax is elevated $20^{\circ}-30^{\circ}$ ), provide a direct working angle to the sellar pathology, and maintain surgeon orientation with the midline. ${ }^{32}$ Image guidance is used in all operations. Abdominal fat grafts are ordinarily taken from the subumbilical region if a CSF leak is identified. ${ }^{39}$ Depending on the size of the skull base defect, a vascularized nasoseptal flap can be harvested. ${ }^{16}$ One dose of antibiotic with primarily gram-positive coverage is given routinely within 60 minutes of incision and continued in the postoperative period only if nasal packing is placed, which occurs rarely. Patients with preoperative fasting cortisol levels below $10 \mu \mathrm{g} / \mathrm{dl}$ are given a steroid bolus preoperatively consisting of $50-100 \mathrm{mg}$ hydrocortisone.

\section{Postoperative Management}

In the immediate postoperative period, all patients undergoing transsphenoidal surgery follow standard orders, regardless of underlying pathology (Table 3). Patients undergo assessments of serum sodium and urine-specific gravity every 6 hours and serum cortisol daily while in the hospital. Cortisol is best assessed in the fasting state in the early morning, as this is the typical physiological peak. ${ }^{27}$ In our patients with a diagnosis of Cushing's disease, cortisol is checked every 6 hours, and replacement is only begun after cortisol levels reach subphysiological levels (typically cortisol $<5 \mu \mathrm{g} / \mathrm{dl}$ with symptoms of ad- 
TABLE 3. Postoperative orders for patients who have undergone transsphenoidal surgery

\begin{tabular}{|c|c|}
\hline Order & Rationale \\
\hline When tolerating clear liquids, discontinue IV fluids & Prevent SIADH/DI; allow for self-regulation \\
\hline Restrict oral fluid intake to $1 \mathrm{~L}$ daily & Prevent SIADH \\
\hline Visual field checks 4 times daily & $\begin{array}{l}\text { Monitor for new visual field deficits, which may be indicative of } \\
\text { postop hemorrhage or may require reop }\end{array}$ \\
\hline Daily patient weights using the same scale \& at the same time & Monitor fluid retention \\
\hline Nose \& abdominal wounds examined each shift & Monitor for bleeding, surgical site infection \\
\hline Afrin \& saline spray start on postop day 2 & Improve patient satisfaction, wound healing \\
\hline
\end{tabular}

IV = intravenous; SIADH = syndrome of inappropriate antidiuretic hormone.

renal insufficiency or nadir $<2 \mu \mathrm{g} / \mathrm{dl}$ at any point). The more quickly cortisol reaches a subphysiological level, the more likely the patient is to have achieved definitive surgical remission. ${ }^{44,47,50}$ Upon reaching nadir, hydrocortisone is typically begun at $40 \mathrm{mg}$ in the morning and $20 \mathrm{mg}$ in the evening and monitored closely postoperatively. If patients develop symptoms of hypocortisolemia as steroids are begun or tapered, the daily doses are increased, typically not higher than $60 \mathrm{mg}$ in the morning and $30 \mathrm{mg}$ in the evening, and kept at this dose until a taper is tolerated by the patient. For patients with acromegaly, assessment of growth hormone level is an inpatient procedure, with insulin-like growth factor-1 measured at the 3-month followup visit. For patients with prolactinomas, serum prolactin is measured daily as an inpatient procedure until it reaches a nadir, and then is rechecked at the 6-week follow-up visit. Fluid intake and output are monitored closely during the postoperative period to assess for fluid retention or diabetes insipidus (DI). The use of desmopressin for treatment of DI should be reserved for patients with a sodium level above $145 \mathrm{mEq} / \mathrm{L}$ and inability to provide adequate fluid intake to achieve euvolemia, or in cases where nocturia is interfering with sleep. Visual field checks are performed at least 3 times daily, both to identify postoperative adverse events, such as hemorrhage, and also to monitor for symptom improvement. Pain is managed without narcotics in the vast majority of cases, which prevents oversedation and promotes early mobility, which is highly encouraged. Patients with significant pain occasionally require intravenous ketorolac in addition to the standard regimen of acetaminophen and nonopioid analgesics. Postoperative NSAIDs (e.g., ibuprofen) are equally effective as opioids in most cases involving minimal trauma to the sinonasal structures..$^{33}$ Patients with Cushing's disease are at increased risk of thromboembolic events and thus we typically start low-dose $(81 \mathrm{mg})$ aspirin administration for these patients on the 1st postoperative day ${ }^{45}$ Aspirin, which has significant antiplatelet effects, has not resulted in a higher incidence of postoperative bleeding in our experience. Thus, NSAID use for pain starting on the 1st postoperative day is typically well tolerated. Because of the increased risk of postoperative bleeding in patients who receive NSAIDs, we use intravenous ketorolac rarely, and never in combination with aspirin. We are also careful to avoid NSAID use in patients who are prone to bleeding, either based on preoperative workup or on intraoperative assessment of bleeding propensity (even in the context of a normal coagulation and platelet profile). In patients without Cushing's disease, venous thromboembolism prophylaxis is achieved with pneumatic boots and early ambulation, and therefore no subcutaneous heparin is routinely used. Only rarely will postoperative patients require admission to the neuroscience ICU, but having this level of care available is imperative should any patients experience significant intraoperative complications. In our practice, indications for admission to the neuroscience ICU include: 1) need for close postoperative monitoring of vision, 2) evidence of a particularly hemorrhagic lesion at risk for postoperative hematoma, and 3) patients with severe medical comorbidities. Admission to the ICU typically only occurs for patients with large lesions with suprasellar extension.

After a typical hospitalization of 2-3 days, patients with sellar pathology are discharged with consistent postdischarge instructions (Table 4). During the 1st week postoperatively, all patients are instructed to limit daily water intake to $1 \mathrm{~L}$, and all patients are discharged with a standard 1-L hospital water pitcher. ${ }^{6}$ In patients with Cushing's disease who enter adrenal insufficiency postoperatively, hyponatremia can occur due to release of antidiuretic hormone as a vasopressor..$^{35}$ Fluid restriction helps to limit the occurrence of hyponatremia in this setting, and careful steroid repletion, as above, precludes development of complications of adrenal insufficiency. During the first 6 weeks postoperatively, patients with obstructive sleep apnea, particularly common among patients with acromegaly, are instructed to refrain from using home CPAP (continuous positive airway pressure) machines until the nasal mucosa heals. Patients return to clinic 1 week postoperatively for evaluation, including repeat measurement of serum sodium and serum cortisol, and physical examination to assess for possible postoperative complications, including CSF leak and meningitis. Patients then return 6 weeks postoperatively for another repeat pituitary and endocrine assessment, often accompanied by an appointment with otolaryngology for a reevaluation of healing in the posterior nasal cavity. Patients then return for a 3-month follow-up visit, which includes definitive postoperative MRI. Among this cohort of patients, the overall readmission rate was 9.0\% (92/1023). Prior to 2015, when mandatory postoperative fluid restriction was implemented, the rate was $10.4 \%$ (73/702) versus $5.9 \%$ after (19/321). Assuming there is no residual lesion and there have been no complications, typical follow-up in our practice entails annual follow-up visits with brain MRI for several years when indicated. 
TABLE 4. Postdischarge instructions for patients who have undergone transsphenoidal surgery

\begin{tabular}{ll}
\hline \multicolumn{1}{c}{ Order } & \multicolumn{1}{c}{ Rationale } \\
\hline Restrict oral fluid intake to $1 \mathrm{~L}$ daily until 1-wk postop appointment & Prevention of SIADH ${ }^{19}$ \\
\hline Only drink when thirsty & Prevention of dysnatremia \\
\hline $\begin{array}{l}\text { Saline nasal spray at least twice per day } \\
\text { No bending or lifting >30 lbs for 4-6 wks }\end{array}$ & Improve patient satisfaction, wound healing \\
\hline $\begin{array}{l}\text { Report any of the following symptoms: nausea, vomiting, fatigue, } \\
\text { severe headache, stiff neck, fever }\end{array}$ & Prevention of CSF leak \\
\hline $\begin{array}{l}\text { Excessive thirst \& frequent urination } \\
\text { Clear nasal drainage with headache }\end{array}$ & May indicate dysnatremia \\
\hline
\end{tabular}

\section{Discussion}

Patients who undergo transsphenoidal surgery for sellar disease require careful perioperative care due to the delicate nature of pituitary function and the risks of complications during the postoperative period. In particular, the convergence of numerous disciplines (neurosurgery, endocrinology, anesthesiology, neuroophthalmology, and otolaryngology) in the care of these patients necessitates effective communication about diagnostic evaluations and perioperative management. Our practice incorporates several evidence-based recommendations for the care of patients during the period of transsphenoidal surgery, but there is a lack of high-quality, randomized evidence because it is impossible to perform randomized controlled trials for each of the small variations in clinical practice that may affect patient outcomes. In the absence of this evidence, and in light of the implausibility of randomized studies clarifying the effectiveness of certain practices, we reviewed and presented here our own institution's practices as a guide by which perioperative care of the patient with sellar pathology can be approached.

Given the complexity of lesions in the sella, multidisciplinary care, preferably at a tertiary or quarternary care center, is preferred. ${ }^{5,9,28}$ These centers allow for coordination of care from multiple specialists, with access to highquality imaging and treatment technologies and a high level of neurocritical care, if necessary. Care for patients at our institution occurs through a multidisciplinary pituitary/neuroendocrine center, which incorporates care by neurosurgeons, neuroendocrinologists, neuroradiologists, otolaryngologists, neuroophthalmologists, and neuropathologists. When patients arrive for consultation, they are evaluated by both a neurosurgeon and a neuroendocrinologist, who each discuss with the patient the risks and benefits of surgery and other possible options for treatment. These relationships are carried through follow-up, with input from neuropathologists in the postoperative period and neuroradiologists at each radiological assessment. The benefit of such an arrangement is typically realized by improved accuracy of diagnosis in patients with acromegaly and Cushing's disease, which requires the interpretation of numerous and often specialized diagnostic tests (oral glucose tolerance test, 24-hour urine free cortisol, latenight salivary cortisol, dexamethasone suppression test, inferior petrosal sinus sampling [IPSS]). For example, we perform IPSS only after the criteria for the diagnosis of
Cushing's disease are established according to current guidelines in order to distinguish a central pituitary source from an ectopic source. ${ }^{34,36}$ Interpretation of IPSS results can be challenging, and the inappropriate use of IPSS may result in false-positive results. Multidisciplinary follow-up is also essential for monitoring and diagnosing disease recurrence.

Overall, the care of patients who are undergoing transsphenoidal surgery should be directed according to the expected timeline for these patients (Table 5). Preoperatively, patients require careful evaluation to assess pituitary function and to plan operative strategies. In our practice, this includes multidisciplinary evaluation in the outpatient setting, with detailed laboratory and neuroradiological assessment. Often, additional consultations are needed to ensure appropriate management, and many of our patients are assessed preoperatively by otolaryngologists in the case of complex nasal and sinus anatomy. Intraoperative management is also carefully standardized according to a previously published surgical checklist. ${ }^{23}$ All operations incorporate intraoperative image guidance, which helps to ensure accurate and safe surgery.

During the immediate postoperative period, patients who have undergone transsphenoidal surgery are at risk of several complications, irrespective of their underlying sellar pathology. These include hyponatremia, hypopituitarism, and CSF leak, among others. ${ }^{11,31}$ Rates of hyponatremia reported in the literature vary widely, ranging from $3.6 \%$ to $19.8 \% .{ }^{10}$ We recently reported an overall rate of readmission for hyponatremia after transsphenoidal surgery of $2.5 \%$, with no readmissions in 203 consecutive operations after institution of mandatory fluid restriction of $1 \mathrm{~L}$ per day in all patients for 1 week postoperatively. ${ }^{6}$ As a result of this study, we now recommend mandatory $1 \mathrm{~L}$ per day fluid restriction for all posttranssphenoidal patients until the 1-week postoperative appointment, at which point the restriction is liberalized if serum sodium is normal.

Hypopituitarism after transsphenoidal surgery is more frequent in patients with large or invasive lesions and is common in the postoperative period for patients with functioning adenomas, who may experience substantial shifts in levels of pituitary hormones. ${ }^{3,31,48}$ Replacement of pituitary hormones is a crucial aspect of posttranssphenoidal surgery care, and consideration of replacement must begin even before the operation, by discussing with 
TABLE 5. Postoperative management of patients undergoing transsphenoidal surgery, including typical postoperative follow-up schedule, diagnostic evaluation, and monitoring or adverse events

\begin{tabular}{|c|c|c|c|c|c|c|}
\hline & Preoperative & Inpatient & POD7 & POW6 & POM3 & POY1 \\
\hline $\begin{array}{l}\text { Diagnostic } \\
\text { Tests }\end{array}$ & $\begin{array}{l}\text { - Physical exam; } \\
\text { - MRI brain/pituitary } \\
\text { - CBC/BMP/PT/INR } \\
\text { - Serum ACTH, cortisol, } \\
\text { PRL, GH, IGF-1, FSH, } \\
\text { LH, testosterone/es- } \\
\text { trogen, TSH, FT4 } \\
\text { - Visual fields }\end{array}$ & $\begin{array}{l}\text { - Daily serum sodium } \\
\text { \& cortisol } \\
\text { - Visual field checks } 4 \\
\text { times daily } \\
\text { - Physical exam }\end{array}$ & $\begin{array}{l}\text { - Serum sodium } \\
\text { - Serum cortisol } \\
\text { - Physical exam }\end{array}$ & $\begin{array}{l}\text { - Full pituitary } \\
\text { endocrine } \\
\text { panel } \\
\text { - Physical exam }\end{array}$ & $\begin{array}{l}\text { - MRI brain/pituitary } \\
\text { - Pituitary hor- } \\
\text { mones for func- } \\
\text { tioning lesions } \\
\text { - Physical exam }\end{array}$ & $\begin{array}{l}\text { - MRI brain/pituitary } \\
\text { - Pituitary hor- } \\
\text { mones for func- } \\
\text { tioning lesions } \\
\text { - Physical exam } \\
\text { - Optic fields when } \\
\text { applicable }\end{array}$ \\
\hline $\begin{array}{l}\text { Management } \\
\text { Considerations }\end{array}$ & $\begin{array}{l}\text { - Consider additional } \\
\text { consults as needed } \\
\text { - Assess preop pituitary } \\
\text { function }\end{array}$ & $\begin{array}{l}\text { - AMS, pain, visual } \\
\text { field changes: con- } \\
\text { sider hemorrhage or } \\
\text { meningitis } \\
\text { - Common complica- } \\
\text { tions: hyponatremia, } \\
\text { hemorrhage, epi- } \\
\text { staxis, CSF leak }\end{array}$ & $\begin{array}{l}\text { - Discuss prelimi- } \\
\text { nary pathology } \\
\text { - Common } \\
\text { complications: } \\
\text { delayed hypo- } \\
\text { natremia, CSF } \\
\text { leak, meningi- } \\
\text { tis, epistaxis }\end{array}$ & $\begin{array}{l}\text { - Assess for re- } \\
\text { turn of pituitary } \\
\text { function in pa- } \\
\text { tients w/ preop } \\
\text { hypopituitarism } \\
\text { - Assess } \\
\text { response to } \\
\text { surgery }\end{array}$ & $\begin{array}{l}\text { - Discuss final } \\
\text { pathology } \\
\text { - Assess for GTR }\end{array}$ & $\begin{array}{l}\text { - Monitor for lesion } \\
\text { recurrence } \\
\text { - Continue annual } \\
\text { MRI follow-ups, } \\
\text { for at least } 5 \\
\text { years of stability }\end{array}$ \\
\hline
\end{tabular}

AMS = altered mental status; $\mathrm{BMP}=$ basic metabolic panel; $\mathrm{CBC}=$ complete blood count; FT4 = free T4; GTR = gross-total resection; INR = international normalized ratio; $\mathrm{POD}=$ postoperative day; $\mathrm{POM}=$ postoperative month; $\mathrm{POW}=$ postoperative week; $\mathrm{POY}=$ postoperative year; $\mathrm{PT}=$ prothrombin time.

patients the possibility of requiring lifelong replacement therapy (Table 6). ${ }^{31}$ Replacement of physiological cortisol can be achieved with either hydrocortisone (twice daily) or prednisone (once or twice daily), usually with lower doses in the evening to improve sleep. It is imperative to instruct patients to report symptoms of hypocortisolemia, including fatigue, weight loss, nausea, and syncope, and to increase intake during periods of illness. Thyroid replacement is achieved with daily levothyroxine dosing, and replacement of sex hormones can be achieved with testosterone in men (gel, patches, or depot injections are appropriate, depending on patient preference), versus oral contraceptive agents or conjugated estrogen tablets in women. We previously reported a rate of new-onset hormone deficiency after transsphenoidal surgery for pituitary macroadenoma of
$6.3 \%$, with patients with recurrent lesions and apoplexy at higher risk. ${ }^{24}$ Diabetes insipidus (DI), in this context often the result of abnormally low levels of antidiuretic hormone resulting in profuse, dilute urine, can be carefully treated with desmopressin if the serum sodium rises above 145 $\mathrm{mEq} / \mathrm{L}$. Although often transient, DI after transsphenoidal surgery can infrequently be a permanent issue. We recently reported an overall rate of DI after transsphenoidal surgery of $14.7 \%$ and a rate of permanent DI of $4.6 \%$.

Postoperative CSF leak after transsphenoidal surgery can occasionally be treated conservatively with lumbar drainage, but it often requires reoperation for repair of the skull base defect. ${ }^{17,38}$ Previously identified predictors of CSF leak post-transsphenoidal surgery include body mass index, identification of intraoperative leak, and pre-

TABLE 6. Recommended hormone replacement strategies for patients requiring pituitary hormone replacement after transsphenoidal surgery

\begin{tabular}{|c|c|c|c|}
\hline Axis Deficiency & Replacement Medication & Initial Replacement Dose* & Notes \\
\hline Cortisol & Hydrocortisone or prednisone & $\begin{array}{l}\text { Hydrocortisone: } 20 \text { mg qAM, } 10 \text { mg qPM; } \\
\text { prednisone: } 5 \text { mg qAM, } 2.5 \text { mg qPM }\end{array}$ & $\begin{array}{l}\text { Cortisol best measured in fasting state, early } \\
\text { morning }\end{array}$ \\
\hline Thyroid & Levothyroxine & $75 \mu \mathrm{q} \mathrm{D}$ & \\
\hline $\mathrm{GH}$ & Somatotropin & $\begin{array}{l}\text { Approximately } 0.2 \mathrm{mg} \mathrm{SC} \mathrm{qD} \text {, depending } \\
\text { on injection type }\end{array}$ & $\begin{array}{l}\text { IGF-1 is more appropriate than } \mathrm{GH} \text { for monitoring } \\
\text { of GH function due to lower daily variability }\end{array}$ \\
\hline Testosterone & Testosterone replacement & $\begin{array}{l}\text { Depends on replacement type (gel vs } \\
\text { injection vs patch, etc.) }\end{array}$ & \\
\hline Estrogen & OCPs or conjugated estrogens & $\begin{array}{l}\text { Should be tailored based on replacement } \\
\text { type \& menopausal status }\end{array}$ & \\
\hline $\mathrm{ADH}$ & Desmopressin & $0.05 \mathrm{mg} \mathrm{qHS}$, may increase to $0.1 \mathrm{mg}$ qHS & $\begin{array}{l}\text { Careful replacement \& monitoring for transient vs } \\
\text { permanent } \mathrm{DI}\end{array}$ \\
\hline
\end{tabular}

$\mathrm{ADH}=$ antidiuretic hormone; $\mathrm{OCP}=$ oral contraceptive pill; $\mathrm{qAM}=$ every morning, $\mathrm{qD}$ = every day; $\mathrm{qHS}=$ every day at bedtime; $\mathrm{qPM}=$ every evening; $\mathrm{SC}=$ subcutaneously.

* These represent initial doses for typical patients but should be tailored to patient characteristics, including weight and signs and symptoms of excess or deficiency. 
operative hydrocephalus, with rates ranging from $2.6 \%$ to $11 \% .17,38,48$ Our practice commonly incorporates abdominal fat grafting as a method of preventing CSF leak, and collaboration with colleagues in otolaryngology can help ensure adequate repair of the skull base defect using nasal septal flaps if needed.1,16,39 Lumbar drainage is rarely used due to the risk of infection with prolonged intrathecal catheter use, as well as the efficacy of bolstering the initial reconstruction in the operating room. Recent evidence suggests that use of perioperative lumbar drain is effective in reducing the rate of postoperative CSF leak in patients undergoing endoscopic endonasal surgery. ${ }^{29,53}$ Upon discharge, patients must be instructed to return to the clinic at any sign of continuous clear drainage from the nose.

Long-term follow-up in these patients is imperative to assess for recurrence of the initially resected lesion. ${ }^{52}$ Our practice recommends that all patients return to the clinic at 3 months and 1 year postoperatively, at a minimum, with most patients returning annually for follow-up subsequently. At each of these appointments, patients are reevaluated by both a neurosurgeon and a neuroendocrinologist, and the patients undergo MRI of the brain and pituitary. At the 3-month postoperative visit, this MRI scan serves to evaluate the effect of surgery and to assess for the extent of resection. At the ensuing annual visits, MRI scans help the clinician assess for lesion recurrence. Signs of recurrence of the initial lesion that would merit repeat imaging outside of this routine include worsening or returning symptoms, such as headache, visual field deficits, or endocrinological symptoms, which are often reported by the patient or detected on physical examination. In the case of functioning tumors, laboratory evaluation can occasionally identify recurrence prior to radiological evaluation. In some cases, patients who have undergone transsphenoidal surgery may require adjuvant treatment for residual or recurrent lesions. ${ }^{21,30}$ These treatments may include radiation therapy or medical therapy, as appropriate, but a complete review of these treatments is beyond the scope of this manuscript. ${ }^{19,25,31,37}$

In this paper, we have reviewed the practices for perioperative care for patients who have undergone transsphenoidal surgery at our institution. This experience incorporates clinical data from over 1000 operations, and aims to serve as an overview for appropriate management of these patients, who often require complicated perioperative care. Several limitations are present in this study. First, this is a retrospective case series and is limited by this aspect of our data. To alleviate any bias, we presented here a complete record of consecutive operations by the senior author. It is also important to note that the outcomes reported at our institution may not necessarily be the result of the postoperative management strategies in place at our institution but rather may be confounded by the surgical experience of the senior author, or by other factors such as institution volume or experience. ${ }^{48}$ Minor variations in some clinical practices from center to center may not have substantial effects on clinical outcomes, and the practices presented here are meant to serve as a guide by which postoperative care after transsphenoidal operations can be approached. Given the diversity of lesions that can affect this region, perioperative care should of course be tailored to the spe- cific patient according to medical history, lesion characteristics, functional status, and endocrine function.

\section{Conclusions}

Patients with sellar lesions who undergo transsphenoidal surgery require complex, multidisciplinary postoperative care to monitor for common adverse events and improve outcomes, but there is a dearth of high-quality evidence guiding most perioperative practices. Here, we reviewed practices at our institution across more than 1000 transsphenoidal operations that may help ensure successful patient outcomes.

\section{Acknowledgments}

D.J.C. received a grant from the National Institutes of Health (grant no. F30 CA235791).

\section{References}

1. Abou-Al-Shaar H, Zaidi HA, Cote DJ, Laws ER Jr: Bolstering the nasoseptal flap using sphenoid sinus fat packing: a technical case report. World Neurosurg 99:813.e1-813.e5, 2017

2. Almutairi RD, Muskens IS, Cote DJ, Dijkman MD, Kavouridis VK, Crocker E, et al: Gross total resection of pituitary adenomas after endoscopic vs. microscopic transsphenoidal surgery: a meta-analysis. Acta Neurochir (Wien) 160:10051021,2018

3. Alzhrani G, Sivakumar W, Park MS, Taussky P, Couldwell WT: Delayed complications after transsphenoidal surgery for pituitary adenomas. World Neurosurg 109:233-241, 2018

4. Barbot M, Daidone V, Zilio M, Albiger N, Mazzai L, Sartori MT, et al: Perioperative thromboprophylaxis in Cushing's disease: What we did and what we are doing? Pituitary 18:487-493, 2015

5. Brennan MD, Jackson IT, Keller EE, Laws ER Jr, Sather AH: Multidisciplinary management of acromegaly and its deformities. JAMA 253:682-683, 1985

6. Burke WT, Cote DJ, Iuliano SI, Zaidi HA, Laws ER: A practical method for prevention of readmission for symptomatic hyponatremia following transsphenoidal surgery. Pituitary 21:25-31, 2018

7. Burke WT, Cote DJ, Penn DL, Iuliano SL, McMillen K, Laws ER: Diabetes insipidus after endoscopic transsphenoidal surgery. Neurosurgery [in press], 2020

8. Burke WT, Penn DL, Castlen JP, Donoho DA, Repetti CS, Iuliano S, et al: Prolactinomas and nonfunctioning adenomas: preoperative diagnosis of tumor type using serum prolactin and tumor size. J Neurosurg [epub ahead of print June 14, 2019. DOI: 10.3171/2019.3.JNS19121]

9. Casanueva FF, Barkan AL, Buchfelder M, Klibanski A, Laws ER, Loeffler JS, et al: Criteria for the definition of Pituitary Tumor Centers of Excellence (PTCOE): a Pituitary Society statement. Pituitary 20:489-498, 2017

10. Cote DJ, Alzarea A, Acosta MA, Hulou MM, Huang KT, Almutairi H, et al: Predictors and rates of delayed symptomatic hyponatremia after transsphenoidal surgery: a systematic review [corrected]. World Neurosurg 88:1-6, 2016

11. Cote DJ, Dasenbrock HH, Muskens IS, Broekman MLD, Zaidi HA, Dunn IF, et al: Readmission and other adverse events after transsphenoidal surgery: prevalence, timing, and predictive factors. J Am Coll Surg 224:971-979, 2017

12. Cote DJ, Wiemann R, Smith TR, Dunn IF, Al-Mefty O, Laws ER: The expanding spectrum of disease treated by the transnasal, transsphenoidal microscopic and endoscopic anterior skull base approach: a single-center experience 2008-2015. World Neurosurg 84:899-905, 2015 
13. Ezzat S, Asa SL, Couldwell WT, Barr CE, Dodge WE, Vance ML, et al: The prevalence of pituitary adenomas: a systematic review. Cancer 101:613-619, 2004

14. Freda PU, Beckers AM, Katznelson L, Molitch ME, Montori VM, Post KD, et al: Pituitary incidentaloma: an endocrine society clinical practice guideline. J Clin Endocrinol Metab 96:894-904, 2011

15. Harary M, DiRisio AC, Dawood HY, Kim J, Lamba N, Cho $\mathrm{CH}$, et al: Endocrine function and gland volume after endoscopic transsphenoidal surgery for nonfunctional pituitary macroadenomas. J Neurosurg 131:1142-1151, 2019

16. Harvey RJ, Parmar P, Sacks R, Zanation AM: Endoscopic skull base reconstruction of large dural defects: a systematic review of published evidence. Laryngoscope 122:452-459, 2012

17. Ivan ME, Iorgulescu JB, El-Sayed I, McDermott MW, Parsa AT, Pletcher SD, et al: Risk factors for postoperative cerebrospinal fluid leak and meningitis after expanded endoscopic endonasal surgery. J Clin Neurosci 22:48-54, 2015

18. Jahangiri A, Wagner J, Han SW, Zygourakis CC, Han SJ, Tran MT, et al: Morbidity of repeat transsphenoidal surgery assessed in more than 1000 operations. J Neurosurg 121:6774,2014

19. Jordan JT, Miller JJ, Cushing T, Seijo M, Batchelor TT, Arrillaga-Romany IC, et al: Temozolomide therapy for aggressive functioning pituitary adenomas refractory to surgery and radiation: a case series. Neurooncol Pract 5:64-68, 2018

20. Katznelson L, Laws ER Jr, Melmed S, Molitch ME, Murad MH, Utz A, et al: Acromegaly: an endocrine society clinical practice guideline. J Clin Endocrinol Metab 99:3933-3951, 2014

21. Klibanski A: Clinical practice. Prolactinomas. N Engl J Med 362:1219-1226, 2010

22. Koutourousiou M, Gardner PA, Fernandez-Miranda JC, Paluzzi A, Wang EW, Snyderman CH: Endoscopic endonasal surgery for giant pituitary adenomas: advantages and limitations. J Neurosurg 118:621-631, 2013

23. Laws ER, Wong JM, Smith TR, de Los Reyes K, Aglio LS, Thorne AJ, et al: A checklist for endonasal transsphenoidal anterior skull base surgery. J Neurosurg 124:1634-1639, 2016

24. Laws ER Jr, Iuliano SL, Cote DJ, Woodmansee W, Hsu L, Cho $\mathrm{CH}$ : A benchmark for preservation of normal pituitary function after endoscopic transsphenoidal surgery for pituitary macroadenomas. World Neurosurg 91:371-375, 2016

25. Loeffler JS, Shih HA: Radiation therapy in the management of pituitary adenomas. J Clin Endocrinol Metab 96:19922003, 2011

26. Lonser RR, Nieman L, Oldfield EH: Cushing's disease: pathobiology, diagnosis, and management. J Neurosurg 126:404-417, 2017

27. Loriaux DL: Diagnosis and differential diagnosis of Cushing's syndrome. N Engl J Med 376:1451-1459, 2017

28. McLaughlin N, Laws ER, Oyesiku NM, Katznelson L, Kelly DF: Pituitary centers of excellence. Neurosurgery 71:916926, 2012

29. Mehta GU, Oldfield EH: Prevention of intraoperative cerebrospinal fluid leaks by lumbar cerebrospinal fluid drainage during surgery for pituitary macroadenomas. J Neurosurg 116:1299-1303, 2012

30. Melmed S: Medical progress: acromegaly. N Engl J Med 355:2558-2573, 2006

31. Molitch ME: Diagnosis and treatment of pituitary adenomas: a review. JAMA 317:516-524, 2017

32. Nemergut EC, Dumont AS, Barry UT, Laws ER: Perioperative management of patients undergoing transsphenoidal pituitary surgery. Anesth Analg 101:1170-1181, 2005

33. Nguyen KK, Liu YF, Chang C, Park JJ, Kim CH, Hondorp B, et al: A randomized single-blinded trial of ibuprofen- versus opioid-based primary analgesic therapy in outpatient otolaryngology surgery. Otolaryngol Head Neck Surg 160:839846, 2019

34. Nieman LK, Biller BMK, Findling JW, Newell-Price J, Savage MO, Stewart PM, et al: The diagnosis of Cushing's syndrome: an Endocrine Society Clinical Practice Guideline. J Clin Endocrinol Metab 93:1526-1540, 2008

35. Oelkers W: Hyponatremia and inappropriate secretion of vasopressin (antidiuretic hormone) in patients with hypopituitarism. N Engl J Med 321:492-496, 1989

36. Oldfield EH, Doppman JL, Nieman LK, Chrousos GP, Miller DL, Katz DA, et al: Petrosal sinus sampling with and without corticotropin-releasing hormone for the differential diagnosis of Cushing's syndrome. N Engl J Med 325:897-905, 1991

37. Pashtan I, Oh KS, Loeffler JS: Radiation therapy in the management of pituitary adenomas. Handb Clin Neurol 124:317-324, 2014

38. Patel PN, Stafford AM, Patrinely JR, Smith DK, Turner JH, Russell PT, et al: Risk factors for intraoperative and postoperative cerebrospinal fluid leaks in endoscopic transsphenoidal sellar surgery. Otolaryngol Head Neck Surg 158:952960, 2018

39. Roca E, Penn DL, Safain MG, Burke WT, Castlen JP, Laws ER: Abdominal fat graft for sellar reconstruction: retrospective outcomes review and technical note. Oper Neurosurg (Hagerstown) 16:667-674, 2019

40. Scangas GA, Laws ER Jr: Pituitary incidentalomas. Pituitary 17:486-491, 2014

41. Seidman PA, Kofke WA, Policare R, Young M: Anaesthetic complications of acromegaly. Br J Anaesth 84:179-182, 2000

42. Singh H, Essayed WI, Cohen-Gadol A, Zada G, Schwartz TH: Resection of pituitary tumors: endoscopic versus microscopic. J Neurooncol 130:309-317, 2016

43. Smith TR, Hulou MM, Huang KT, Gokoglu A, Cote DJ, Woodmansee WW, et al: Current indications for the surgical treatment of prolactinomas. J Clin Neurosci 22:1785-1791, 2015

44. Smith TR, Hulou MM, Huang KT, Nery B, de Moura SM, Cote DJ, et al: Complications after transsphenoidal surgery for patients with Cushing's disease and silent corticotroph adenomas. Neurosurg Focus 38(2):E12, 2015

45. Van Zaane B, Nur E, Squizzato A, Dekkers OM, Twickler MTB, Fliers E, et al: Hypercoagulable state in Cushing's syndrome: a systematic review. J Clin Endocrinol Metab 94:2743-2750, 2009

46. Zada G, Cavallo LM, Esposito F, Fernandez-Jimenez JC, Tasiou A, De Angelis M, et al: Transsphenoidal surgery in patients with acromegaly: operative strategies for overcoming technically challenging anatomical variations. Neurosurg Focus 29(4):E8, 2010

47. Zada G, Tirosh A, Huang AP, Laws ER, Woodmansee WW: The postoperative cortisol stress response following transsphenoidal pituitary surgery: a potential screening method for assessing preserved pituitary function. Pituitary 16:319325,2013

48. Zaidi HA, Awad AW, Bohl MA, Chapple K, Knecht L, Jahnke H, et al: Comparison of outcomes between a less experienced surgeon using a fully endoscopic technique and a very experienced surgeon using a microscopic transsphenoidal technique for pituitary adenoma. J Neurosurg 124:596-604, 2016

49. Zaidi HA, Cote DJ, Burke WT, Castlen JP, Bi WL, Laws ER Jr, et al: Time course of symptomatic recovery after endoscopic transsphenoidal surgery for pituitary adenoma apoplexy in the modern era. World Neurosurg 96:434-439, 2016

50. Zaidi HA, Penn DL, Cote DJ, Laws ER Jr: Root cause analysis of diagnostic and surgical failures in the treatment of suspected Cushing's disease. J Clin Neurosci 53:153-159, 2018 
51. Zhang Y, Guo X, Pei L, Zhang Z, Tan G, Xing B: High levels of IGF-1 predict difficult intubation of patients with acromegaly. Endocrine 57:326-334, 2017

52. Ziu M, Dunn IF, Hess C, Fleseriu M, Bodach ME, Tumialan LM, et al: Congress of Neurological Surgeons systematic review and evidence-based guideline on posttreatment follow-up evaluation of patients with nonfunctioning pituitary adenomas. Neurosurgery 79:E541-E543, 2016

53. Zwagerman NT, Wang EW, Shin SS, Chang YF, FernandezMiranda JC, Snyderman CH, et al: Does lumbar drainage reduce postoperative cerebrospinal fluid leak after endoscopic endonasal skull base surgery? A prospective, randomized controlled trial. J Neurosurg 131:1172-1178, 2019

\section{Disclosures}

The authors report no conflict of interest concerning the materials or methods used in this study or the findings specified in this paper.

\section{Author Contributions}

Conception and design: all authors. Acquisition of data: Cote, Laws. Analysis and interpretation of data: Cote, Laws. Drafting the article: all authors. Critically revising the article: all authors. Reviewed submitted version of manuscript: all authors. Approved the final version of the manuscript on behalf of all authors: Cote. Statistical analysis: Cote. Administrative/technical/material support: Cote. Study supervision: Laws.

\section{Correspondence}

David J. Cote: Brigham and Women's Hospital, Harvard Medical School, Boston, MA. david_cote@hms.harvard.edu. 